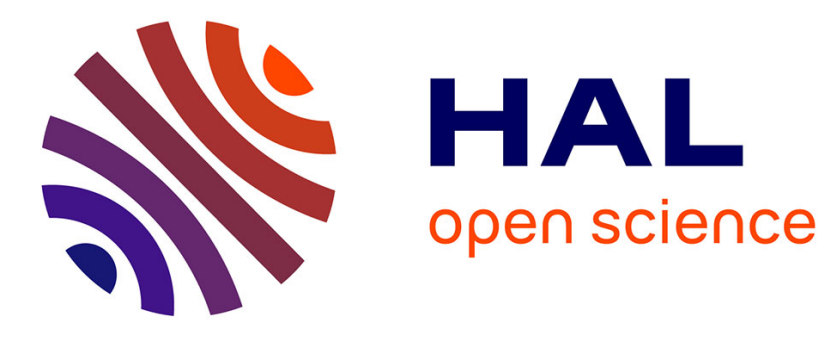

\title{
Spondyloarthritis and sarcoidosis: Related or fake friends? A systematic literature review
}

Simon Cadiou, Francois Robin, Raphaël Guillin, Aleth Perdriger, Stéphane

Jouneau, Nicolas Belhomme, Guillaume Coiffier, Pascal Guggenbuhl

\section{- To cite this version:}

Simon Cadiou, Francois Robin, Raphaël Guillin, Aleth Perdriger, Stéphane Jouneau, et al.. Spondyloarthritis and sarcoidosis: Related or fake friends? A systematic literature review. Joint Bone Spine, 2020, 87 (6), pp.579-587. 10.1016/j.jbspin.2020.06.011 . hal-02929980

\section{HAL Id: hal-02929980 \\ https://hal.science/hal-02929980}

Submitted on 10 Sep 2020

HAL is a multi-disciplinary open access archive for the deposit and dissemination of scientific research documents, whether they are published or not. The documents may come from teaching and research institutions in France or abroad, or from public or private research centers.
L'archive ouverte pluridisciplinaire HAL, est destinée au dépôt et à la diffusion de documents scientifiques de niveau recherche, publiés ou non, émanant des établissements d'enseignement et de recherche français ou étrangers, des laboratoires publics ou privés. 
Spondyloarthritis and sarcoidosis: related or fake friends? A systematic literature review

Cadiou S (1), Robin F (1), Guillin R (2), Perdriger A (1), Jouneau S (3), Belhomme N (4), Coiffier G (1), and Guggenbuhl P $(1,5)$.

(1) Department of Rheumatology, Rennes University Hospital, 35000, Rennes, France.

(2) Department of Medical Imaging, Rennes University Hospital, 35000, Rennes, France.

(3) Department of Respiratory Medicine, Rennes University Hospital, Rennes, France. University of Rennes 1, Rennes, France. INSERM-IRSET UMR1085, Rennes, France.

(4) Internal Medicine Department, Rennes University Hospital, 35000, Rennes, France.

Highlights

- Spondyloarthritis and sacroiliitis are regularly associated to sarcoidosis, especially in cases of inflammatory back pain

- A granulomatous involvement of pelvic bones in sarcoidosis can occur and mimic sacroiliitis; unilateral changes on X-rays are suggestive of granulomatous involvement.

- True sacroiliac joint arthropathy associated to sarcoidosis is still matter of discussion.

- Imaging modalities used to evaluate sacroiliac joint in sarcoidosis are still heterogeneous.

CHU Rennes, Univ Rennes, INSERM, Institut NUMECAN (Nutrition Metabolisms and Cancer), F-35000, Rennes, France. UMR INSERM U 1241, University of Rennes 1, 35000, Rennes, France. 


\section{Abstract:}

Background: Sarcoidosis and spondyloarthritis $(\mathrm{SpA})$ have been regularly associated. Bone iliac granulomas have also been described. We propose herein a systematic review of rheumatologic axial manifestations of sarcoidosis.

Methods: PubMed and the Cochrane Library were used to conduct this systematic literature review. Case reports and cross-sectional studies were reviewed according to Preferred Reporting Items for Systematic reviews and Meta-Analyses (PRISMA) guidelines.

Results: A total of 41 articles were eligible. Three cross-sectional studies on the association between SpA and sarcoidosis showed a prevalence of sacroiliitis and SpA ranging from 12.9 to $44.8 \%$ and 12.9 to $48.3 \%$ in inflammatory back pain (IBP) subgroups, respectively. However, the IBP definitions and sacroiliac joint (SIJ) imaging modalities (X-rays or magnetic resonance imaging) were heterogeneous, and X-ray was mainly used for sacroiliitis diagnosis (in $78 \%$ of cases). Thirty-one case-report articles of the sarcoidosis-sacroiliitis association were identified, representing 35 patients. ASAS criteria for SpA were met in half of cases (16/32) and 46\% (12/26) had HLA B27 positivity. Sarcoidosis occurred after sacroiliac symptoms in $47 \%$ of cases. In the seven case-report articles with granulomatous sacroiliac bone involvement, unilateral involvement was significatively higher than in the sarcoidosis-sacroiliitis group $(p<0.001)$.

Conclusion: Literature analysis found a good evidence of the association between SpA and sarcoidosis, and special attention should be given to patients reporting IBP. Unilateral sacroilitis may raise suspicion of granulomatous bone involvement, distinct from sacroiliitis. Imaging modalities used to study the SIJ in patients with sarcoidosis have been heterogeneous and further investigation is needed.

Keywords: sarcoidosis; sacroiliitis; sacroiliac joint; spondyloarthritis; bone; granulomatous 


\section{Introduction}

Sarcoidosis is a granulomatous disease of unknown origin[1]. Lungs with mediastinal lymph nodes are frequently involved, but granulomas can affect all organs, among which the skin, lymphoid system, eyes, and liver are the most common[1]. The musculoskeletal system is involved in 4 to $38 \%$ of patients[2], consisting of acute forms, such as Löfgren's syndrome, or chronic presentation, such as sarcoid arthropathy, with synovial sarcoid granuloma. Bone sarcoidosis is rare, reported in 3 to $13 \%$ of sarcoidosis patients[3].Sacroiliitis in sarcoidosis was initially described in 1951 by Verstraeten et al. in a case report[4]. It is characterized by sacroiliac joint (SIJ) inflammation and often inflammatory low back pain. Since the publication of this paper, links between sarcoidosis and sacroilitis have been regularly reported in the literature. Most studies have reported radiographic sacroiliitis or bone iliac involvement but on a limited number of cases[5,6].

The aim of this systematic review was to identify the diagnostic characteristics, including radiological criteria, for sacroiliitis in patients with sarcoidosis and sacroiliac involvement. We included case reports and prospective and retrospective studies.

\section{Methods}

a. Publication search

This systemic review was performed in January 2020 using the Medline (using PubMed) and Cochrane databases. We identified articles in English and French using the Preferred Reporting Items for Systematic Reviews and MetaAnalysis (PRISMA) statement[7]. Keywords used in the search strategy were (sarcoidosis OR sarcoid OR sarcoid*) AND (sacroiliitis OR sacroiliac OR ankylosing spondylitis OR spondyloarthritis $O R$ spondyloarthropathy). Additional relevant papers were identified through other sources, mainly from the bibliographies of previous papers.

b. Inclusion criteria

All study designs (case report, retrospective or prospective, cross-sectional) were included. After the removal of duplicates, we selected papers evaluating the SIJ in patients with sarcoidosis. Sarcoidosis had to be confirmed through histological proof of non-caseating granulomas, with exclusion of other granulomatous diseases, especially mycobacterial infections[8]. We did not include cases of granulomatous reaction following anti-tumor necrosis factor alpha (TNFa) therapy for spondyloarthritis $(\mathrm{SpA})$ or other autoimmune diseases because the immunopathogenesis of sarcoidosis is not well known and because of the iatrogenic link of drug-induced sarcoidosis-like reactions (DISRs)[9] following antiTNFa therapy. DISR due to anti-TNFa therapy is considered to be a differential diagnosis, according to the granulomatous "drug reaction" mentioned in the ATS/ERS/WASOG statement on sarcoidosis[8].

c. Collection data

We collected the following data from the case reports: sex, age at diagnosis, imaging used for the author's diagnosis of sacroiliitis, sacroiliitis according to the ASAS 2009 criteria[10], SIJ score on radiography based on the modified New York (mNY) criteria, ankylosis, HLA B27 status, presence of back pain (mechanical or inflammatory), back pain $\geq 3$ months, age at onset $<45$ years old, features of SpA (inflammatory back pain (IBP), arthritis, enthesitis, dactylitis, uveitis, psoriasis, inflammatory bowel disease, good response to NSAIDs, family history of SpA, elevated CRP), diagnosis of sarcoidosis (granuloma on biopsy and/or Löfgren syndrome), grading of sarcoidosis on thoracic radiography, 
granuloma-affected organs, and temporal relationship of sarcoidosis with SIJ symptoms (before, after, or concurrent diagnosis).

\section{Results}

In total, we identified 317 articles in PubMed, and 37 articles in the Cochrane Library. After removing duplicates and adding five articles identified in the bibliography of previously selected papers, 335 articles were screened. Based on the title and abstract, 265 articles were excluded and 70 were assessed for full-text eligibility. Twenty-nine full-text articles were excluded, mainly due to DISRs following anti-TNFa treatment. Finally, 41 papers were considered for the study. The PRISMA ${ }^{\odot}$-flow diagram is shown in Figure 1. Three of the 41 papers were cross-sectional studies[5,11,12] (summarized in Table 1). Among the remaining 38 case reports, two groups were identified: a sacroilitis-sarcoidosis group $[4,13-$ 42] and a group with granulomatous bone sacroiliac involvement mimicking sacroiliitis[6,43-48]. The main characteristics of the sacroiliitis-sarcoidosis group are summarized in Tables $\mathbf{2}$ and $\mathbf{3}$ and those of the group with sacroiliac bone involvement in Table 4.

a. Cross-sectional studies

In 2005, Erb et al.[11] published the first monocentric cross-sectional cohort study of back pain in a sarcoidosis population, in which 61 patients were analyzed. Almost all patients were Caucasian, with a sex-ratio close to one. Five patients did not meet the ATS/ERS/WASOG criteria for sarcoidosis due to the absence of compatible histology and Lofgren's syndrome, but were nevertheless considered to have sarcoidosis and included in the study. Radiographic evaluation of the SIJ was performed by double reading, but the criteria for a diagnosis of sacroiliitis was not mentioned. The authors considered four patients to have sacroiliitis with only one patient with bilateral involvement. Radiological sacroilitis was considered independently of a SpA diagnosis in this study, but one patient had HLA B27 antigen. There was no difference between patients with or without sacroiliitis in this study. The prevalence of sacroiliitis was estimated to be $6.6 \%(4 / 61)$ in the sarcoidosis population, $8.2 \%(4 / 49)$ in the back-pain sub-group, and $12.9 \%(4 / 31)$ in the IBP subgroup.

Kobak et al.[5] reported six cases of bilateral sacroiliitis scored according to mNY criteria based on standard pelvic radiography in a monocentric cohort of 42 patients with biopsy-proven sarcoidosis. All patients in the X-ray sacroiliitis group had IBP according to Calin criteria. The authors thus diagnosed six cases of SpA according to ASAS 2009 criteria[10]. SpA-sarcoidosis patients were more likely to be female and lacking HLA B27. Eight patients without sacroiliitis also had IBP. The prevalence of sacroiliitis and SpA in the sarcoidosis population was estimated to be $14.3 \%(6 / 42)$ and $43 \%(6 / 14)$ in the IBP subgroup. Sigaux et al.[12] recently published a prospective study of back pain with MRI exploration in a biopsyproven sarcoidosis cohort of 337 patients. Among 64 back-pain patients, 29 had IBP. The diagnosis of sacroiliitis was defined as bone-marrow edema in a compartment of the SIJ on one slice for bilateral lesions or on two consecutive slices for unilateral localization. Two blinded readers (one rheumatologist and one radiologist) analyzed MRI, and a consensus was reached in case of disagreement. Sacroiliitis was diagnosed in 13 patients with IBP ( 5 also had radiographic sacroilitis according to the $\mathrm{mNY}$ criteria). The patient characteristics in the sacroiliitis subgroup were not reported. SpA was diagnosed in all patients with sacroiliitis; one patient with mechanical pain was diagnosed with SpA due to the association of HLA B27 positivity, psoriasis, and enthesitis and one patient had a vertebral inflammatory signal, HLA B27 positivity, and clinical features of SpA. The respective prevalence of sacroiliitis and SpA were estimated 
to be $3.9 \%(13 / 337)$ and $4.5 \%(15 / 337)$ in the sarcoidosis population, $20.3 \%(13 / 64)$ and $23.4 \%(15 / 64)$ in the back-pain subgroup, and $44.8 \%(13 / 29)$ and $48.3 \%$ (14/29) in the IBP subgroup.

b. Sacroiliitis-sarcoidosis case reports[4,13-42]

Thirty-one papers for a total of 35 cases were included for analysis. Data for the back pain characteristics (ASAS criteria for inflammatory or mechanical back pain) were too limited to be specified. ASAS criteria for SpA were applied retrospectively. Back pain with a duration $\geq 3$ months with an age of onset $\leq 45$ years was considered to be inflammatory, except if it was explicitly qualified as mechanical. Sacroilitis was diagnosed on MRI with bone marrow edema or on pelvic radiography (bilateral $\mathrm{mNY}$ grade 2 pelvic radiography or unilateral grade 3 or 4 ). If ASAS criteria were still not met, other clinical features and HLA B27 positivity were also considered for the diagnosis of SpA. The main characteristics are summarized in Tables 2 and 3.Standard pelvic radiography was commonly used to evaluate the SIJ. Four papers did not report the imaging modalities for the diagnosis of sacroilitis. By X-ray, six patients had bilateral grade 2 sacroiliitis, nine patients had unilateral or bilateral grade 3 sacroiliitis, and six patients had sacroiliac ankylosis (grade 4). Two case reports considered the SIJ imaging to be normal[22,38] but were included due to the author's diagnosis of SpA.A biopsy-proven granuloma or Löfgren's syndrome was always reported for sarcoidosis, except for case $n^{\circ} 2$ of Kremer et al.[22], which had a clinical presentation highly suggestive of sarcoidosis without granuloma on carina biopsy.

c. Granulomatous involvement of iliac bones[6,43-48]

We initially selected 11 articles for this subgroup, which was characterized by granulomatous tissue on iliac bone biopsy or imaging suggestive of bone disease. However, sarcoidosis was not diagnosed according to WASOG/ATS criteria in four articles [Appendix A, supplementary data S1; See the supplementary material associated with this article online] due to concurrent mycobacterial identification in bone or pulmonary samples. Five cases of sarcoidosis had histological proof of a granuloma in an iliac biopsy. For the two remaining cases, Benelhadj et al.[46] suspected a granulomatous lesion based on left sacroiliac joint hyperactivity in $T \mathrm{~T}^{99}$ scintigraphy with a bone island on CT in a patient with peripheral bone involvement and Mijiyawa et al.[44] showed a granuloma on a bone biopsy of T10 and osteosclerotic changes of iliac bone in a patient with multivisceral sarcoidosis. Excluding X-ray imaging, there was no evidence of any real joint damage of the SIJ in this sub-group, on CT [48] or MRI[6].The main characteristics of the seven proven or highly probable cases are summarized in Table 4. All patients had back pain. There were six women and one man, with a median age of 42.0 years $( \pm 12.0 \mathrm{IQR})$. Unilateral involvement of iliac bone on imaging represented $6 / 7$ patients and appeared to be higher in the group with bone involvement than unilateral sacroiliitis in the sarcoidosis-sacroiliitis 
group. A multivisceral granulomatous disease also appeared to be frequent. HLA B27 status was never mentioned in the articles.

\section{Discussion}

Sacroiliac joint arthropathy may be associated with sarcoidosis. Whether or not it is a feature of the disease is still a matter of discussion. Most published papers have studied the association of sarcoidosis with SpA and patients were mostly recruited in rheumatology department if they had IBP. Moreover, the cross-sectional studies always studied back pain and sacroiliitis in a pre-existent sarcoidosis population, whereas most case reports mention a diagnosis of sarcoidosis after the onset of symptoms of sacroiliitis in almost half of the cases. Few authors found a correlation between SpA and sarcoidosis, as recently shown in the general Taiwanese population[49], in which the prevalence of ankylosing spondylitis was estimated to be $3.64 \%$ in the sarcoidosis population versus $0.83 \%$ in the control population (adjusted odds ratio: 3.80 [2.42-5.97]). This prevalence in the sarcoidosis population is close to that found by Sigaux et al[12]. The long mean time interval of $10.4( \pm 7.1)$ years between the beginning of sacroiliac symptoms and sarcoidosis diagnosis could also argue in favor of two different diseases.

Sacroiliac involvement could also be due to a sarcoidosis bone lesion on the iliac or sacral bones[6,45]. Since the first cases of sacroiliac bone involvement were reported in 1951[4], the diagnostic criteria for sarcoidosis have evolved and now include histological proof of a sarcoidosis granuloma and the exclusion of other granulomatous diseases. The recent evolution of bacteriological identification, with new techniques for growth and molecular tools, such as PCR for mycobacteria, could explain some cases of the incorrect diagnosis of sarcoidosis in the presence of granuloma in older articles[15] (Appendix A, supplementary data S1). Nonetheless, the prevalence of bone sarcoidosis (axial and peripheral) may be frequently underestimated because half the cases are asymptomatic[3]. Bone sarcoidosis has been recently described in a new light by Ben Hassin et al. in an 88-patient retrospective multicentric cohort[3]: $39 \%$ of the patients were diagnosed with bone lesions at initial presentation of sarcoidosis, with a median time of 2.8 years between the diagnosis of sarcoidosis and bone involvement. Pelvic bones were involved in $63 \%$ of axial bone sarcoidosis cases, representing $44 \%$ of total bone localization. Patients with bone lesions had significantly higher rates of mediastinal and extra-mediastinal lymph-node involvement, pulmonary involvement, cutaneous manifestations, and hypercalcemia. In addition, $52 \%$ of patients had bone symptoms and among them, 33\% had back or pelvic pain. The treatment of bone sarcoidosis was mainly based on glucocorticoid therapy. This article reported that granulomatous pelvic bone localization, although rare, can occur several years after the initial diagnosis and can clinically mimic SpA with back pain. Imaging, preferring MRI to CT, can help to distinguish a bone involvement from sacroilitis. Bone biopsy therefore appears to be essential if there is any doubt as to the cause of the bone disorder (such as infection, metastasis, or haemopathy) by x-ray, MRI, or CT.

Sarcoidosis could theoretically manifest itself as granulomatous sacroiliac synovitis, similarly to peripheral chronic granulomatous synovitis. However, it may be difficult to differentiate it from SpA sacroiliac synovitis in the absence of histological evidence. No cases of granulomatous synovitis of the sacroiliac joint have been reported to date. Nevertheless, common pathophysiological pathways have been described in SpA and sarcoidosis. As abundant TNFa has been found in the sacroiliac joint of patients with SpA, anti-TNFa therapy has largely demonstrated its efficacy in SpA. TNFa is also involved in granuloma formation and infliximab has been shown to be effective in sarcoidosis[50]. Among the 
articles covered in this review, the anti-TNFa infliximab was used to cure both diseases in four cases[32$34,42]$, with a good outcome, whereas the use of etanercept for SpA worsened the sarcoidosis in another case[30]. This paradoxical worsening with anti-TNFa therapy is now well known[9] and improvement of the granulomatous reaction upon drug discontinuation and the higher prevalence of DISR associated with anti-TNFa therapy than sarcoidosis itself[9] argues for distinct entities. IL-17 produced by T helper 17 (Th17) is another target for SpA treatment and anti-IL-17A monoclonal antibodies, such as secukinumab, are effective in treating SpA[51]. Th17 lymphocytes have also been shown to be increased in granulomas, as well as circulating memory $T$ cells in patients with sarcoidosis[52], suggesting their implication in the pathogenesis of sarcoidosis. On the other hand, an elevated number of IL-17 producing-cells has been associated with a better outcome in Löfgren's syndrome[53], necessitating further study to determine whether IL 17A may be an interesting target in sarcoidosis.

Concerning imaging in sacroiliitis, Sigaux et al.[12] mostly diagnosed sacroiliitis by MRI, whereas X-rays showed sacroiliitis in only $38 \%(5 / 13)$ of their cases. Sacroilitis on MRI and X-ray represented respectively $45.3 \%$ and $17.2 \%$ of patient with inflammatory back pain, $20.3 \%$ and $7.8 \%$ of patient with back pain, and $3.9 \%$ and $1.5 \%$ of the whole population of 337 patients. Using only X-rays, Erb et al.[11] found a similar prevalence of $12.9 \%$ in the IBP subgroup, and $8.2 \%$ in the back-pain sub-group. Kobak et al.[5] found a prevalence of sacroiliitis on X-ray of $43 \%$ in the IBP subgroup, and $14.3 \%$ in the entire sarcoidosis population. These differences can be explained by the difference between populations in the studies. Themean mean age of the patients in the studies was similar, but the duration of sarcoidosis varied: Kobak et al.[5] studied patients with a shorter duration of disease (mean of 17.8 months) versus Erb et al.[11] and Sigaux et al.[12] (means of 9.0 years and 12.2 years, respectively). More importantly, the duration of back pain was only mentioned in the study of Sigaux et al.[12] and lasted an average of $3.6 \pm 5.6$ years in the inflammatory group. Given the mean time from the diagnosis of sarcoidosis to the sacroiliac onset of nine years in ankylosing spondylitis[54], the duration of the evolution of low back pain in the other two papers would have been of interest. Finally, the populations studied were not homogeneous, especially in terms of geographical characteristics, which could influence the genetics and frequency of HLA B27.

Other explanations are possible for the difference in the number of sacroiliitis cases between these studies. The low inter-reader reproducibility and low sensitivity of radiography in diagnosing sacroiliitis is well known[55]. X-ray allows only a two-dimensional view of the SIJ, leading to the potential misdiagnosis of degenerative changes in the antero-inferior ligamentous compartment of the SIJ as sacroiliitis, especially for bilateral grade 2 and erosions[55]. Similarly, sclerosis appears to be associated with being female[56] and could explain the female predominance of HLA B27 negativity in the studies of Kobak et al[5] and Erb et al[11], who used X-rays. Furthermore, MRI shows good specificity but also gives rise to frequent false positives in the diagnosis of sacroiliitis, as it may overestimate sacroiliitis based on bone marrow edema (BME)[57]. In addition, BME in the SIJ has not been shown to correlate with IBP criteria, such as the ASAS 2009 or Calin criteria in a back-pain population[58]; morning stiffness $>60$ minutes was the only pain characteristic associated with BME[58]. In our sacroiliitis-sarcoidosis group, the papers did not provide sufficient detail to evaluate the characteristics of the back pain, such as morning stiffness. On the other hand, the intensity of the hypersignal in short-tau inversion recovery (STIR) sequences could help to distinguish inflammatory changes (with a medium to high score for BME) from degenerative changes (with a low score for BME) correlated with age and not IBP nor ASAS SpA features[56]. Sigaux et al.[12] did not systematically evaluate the SIJ by MRI in case of non-inflammatory back pain (performed for only $9 / 35$ patients), which could have led to underestimation of the number of 
sacroiliitis and Spa cases according to the ASAS criteria. Nevertheless, the study of Sigaux et al. was the only one to evaluate the features of SpA in a mechanical back-pain population. Finally, asymptomatic BME that fulfills the ASAS 2009 criteria for sacroiliitis may be present in $17.2 \%$ of healthy individuals or following physical stress on the SIJs, such as that arising from sports, military training, or childbirth[57], and no SIJ imaging, including MRI, on asymptomatic patients with sarcoidosis has been yet reported in the literature.

In this systematic review, only a few patients in case reports and none in cohorts had a CT evaluation of their SIJs. CT may however be useful for SIJ anatomy and following the structural changes that occur frequently in the general population (approximately $29 \%$ in the $50-59$ year-old population[59]). The study of erosion by CT could also be useful in the diagnosis of sacroiliitis[60], with a strong correlation to HLA B27 and the response to NSAIDs on MRI in cases of IBP[58]. Finally, this literature review raises questions concerning the ASAS 2009 diagnostic criteria for SpA and the accuracy of $x$-rays, MRI, and CT in cases of features such as IBP or HLA B27 positivity in patients with sarcoidosis.

One of the outcomes of this systematic review is the identification of two groups of sarcoidosis patients with sacroiliac involvement. The sacroiliitis-sarcoidosis group, with sarcoidosis patients fulfilling ASAS 2009 criteria for SpA with predominant HLA B27 positivity and inflammatory back pain, and a group with granulomatous iliac bone involvement which seems not to be associated with SpA. The distinction between these two presentations is important in terms of therapeutic issues and evolution. SpA is a chronic disease which needs a long-term follow-up, and non-steroidal anti-inflammatory drugs or antiTNFa therapy. Bone involvement most often requires only corticosteroid therapy, with a good outcome, even if it is sometimes part of a refractory systemic disease requiring other immunosuppressive treatments[3].

\section{Conclusion}

Sacroiliac joint changes in sarcoidosis include sacroilitis related to an association with SpA and granulomatous bone involvement. Sarcoid sacroiliac arthropathy is still discussed. In the presence of back pain, inflammatory symptoms should raise suspicion of SpA. An X-ray could be performed first, but due to the possible higher prevalence of SpA in sarcoidosis and several cases of axial bone sarcoidosis, MRI of the pelvis and the spine must be done in case of unexplained low back pain in a patient with sarcoidosis. In case of bone damage, a bone biopsy can be discussed. The complexity of SIJ imaging in cases of inflammatory back pain, mechanical back pain, or even no pain, highlight the need for further investigation of SIJ in sarcoidosis with clinical and biological evaluation, such as the presence of HLA B27, and with multimodal imaging (MRI and CT).

\section{Financial support}

No financial support or other benefits from commercial sources was provided for this work.

\section{Disclosure of interest}

The authors declare that they have no competing interest.

\section{Appendix A. Supplementary data}

Supplementary data (S1) associated with this article can be found in the online version at ... 


\section{9}

Page 9 of 13 


\section{References}

[1] Valeyre D, Prasse A, Nunes H, Uzunhan Y, Brillet P-Y, Müller-Quernheim J. Sarcoidosis. Lancet 2014;383:1155-67. https://doi.org/10.1016/S0140-6736(13)60680-7.

[2] Goussault C, Albert J-D, Coiffier G, Lamer F, Guillin R, Le Goff B, et al. Ultrasound characterization of ankle involvement in Löfgren syndrome. Joint Bone Spine 2017. https://doi.org/10.1016/j.jbspin.2017.03.004.

[3] Ben Hassine I, Rein C, Comarmond C, Glanowski C, Saidenberg-Kermanac'h N, Meunier B, et al. Osseous sarcoidosis: A multicenter retrospective case-control study of 48 patients. Joint Bone Spine 2019;86:789-93. https://doi.org/10.1016/j.jbspin.2019.07.009.

[4] Verstraeten, J.M., Bekaert, J. Association de spondylite ankylosante et de sarcoidose. 1951;42:149-51.

[5] Kobak S, Sever F, Ince O, Orman M. The prevalence of sacroilitis and spondyloarthritis in patients with sarcoidosis. Int J Rheumatol 2014;2014:289454. https://doi.org/10.1155/2014/289454.

[6] Binicier O, Sari I, Sen G, Onen F, Akkoc N, Manisali M, et al. Axial sarcoidosis mimicking radiographic sacroiliitis. Rheumatol Int 2009;29:343-5. https://doi.org/10.1007/s00296-008-06776.

[7] Moher D, Liberati A, Tetzlaff J, Altman DG, PRISMA Group. Preferred reporting items for systematic reviews and meta-analyses: the PRISMA statement. PLoS Med 2009;6:e1000097. https://doi.org/10.1371/journal.pmed.1000097.

[8] Costabel U, Hunninghake GW. ATS/ERS/WASOG statement on sarcoidosis. Sarcoidosis Statement Committee. American Thoracic Society. European Respiratory Society. World Association for Sarcoidosis and Other Granulomatous Disorders. Eur Respir J 1999;14:735-7. https://doi.org/10.1034/j.1399-3003.1999.14d02.x.

[9] Chopra A, Nautiyal A, Kalkanis A, Judson MA. Drug-Induced Sarcoidosis-Like Reactions. Chest 2018;154:664-77. https://doi.org/10.1016/j.chest.2018.03.056.

[10] Rudwaleit M, van der Heijde D, Landewé R, Listing J, Akkoc N, Brandt J, et al. The development of Assessment of SpondyloArthritis international Society classification criteria for axial spondyloarthritis (part II): validation and final selection. Ann Rheum Dis 2009;68:777-83. https://doi.org/10.1136/ard.2009.108233.

[11] Erb N, Cushley MJ, Kassimos DG, Shave RM, Kitas GD. An assessment of back pain and the prevalence of sacroiliitis in sarcoidosis. Chest 2005;127:192-6. https://doi.org/10.1378/chest.127.1.192.

[12] Sigaux J, Semerano L, Nasrallah T, Nunes H, Bouvry D, Valeyre D, et al. High prevalence of spondyloarthritis in sarcoidosis patients with chronic back pain. Seminars in Arthritis and Rheumatism 2019. https://doi.org/10.1016/j.semarthrit.2019.03.006.

[13] Deshayes P, Desseauve J., Hubert J., Lemercier J.P., Geoffroy Y. Un cas de polyarthrite au cours d'une sarcoidose: Un cas de spondylarthrite ankylosante au cours d'une sarcoidose. Rev Rhum 1965;32:671-4.

[14] Ranfaing J, Banzet ML, Ledoux A, Couetdic G, Clement B. [Letter: Association of sarcoidosis, ankylosing spondylitis and monoclonal immunoglobulin]. Nouv Presse Med 1976;5:1006.

[15] Blanchon P, Paillas J, Lauriat H, Tominez G. [Pelvi-spinal and spinal localizations of BesnierBoeck-Schaumann's sarcoidosis]. Ann Med Interne (Paris) 1976;127:843-8.

[16] Gerster JC, Chappuis P. [Association of an acute sarcoidosis and ankylosing spondylitis in a patient (author's transl)]. Schweiz Rundsch Med Prax 1981;70:2356-9.

[17] Velasco Domínguez E, García Velasco F, Arranz Velasco JL, Mateos Otero J, Ergueta Martín P, López Palma LM. [Vertebral sarcoidosis with ankylosing spondyloarthritis and atlanto-axial luxation]. Rev Clin Esp 1983;168:423-6.

[18] Kchir MM, Mazigh R, Charrad R, Boujnah MR, Chérif W, Baklouti N, et al. [Sacro-iliac involvement in sarcoidosis. Apropos of a case]. Tunis Med 1986;64:961-4. 
[19] Kirkham B, Jobanputra P. Sarcoidosis and spondarthritis. Br J Rheumatol 1988;27:241.

[20] Stucki G, von Felten A, Speich R, Michel BA. Ankylosing spondylitis and sarcoidosis--coincidence or association? Case report and review of the literature. Clin Rheumatol 1992;11:436-9.

[21] Kötter I, Dürk H, Saal JG. Sacroiliitis in sarcoidosis: case reports and review of the literature. Clin Rheumatol 1995;14:695-700.

[22] Kremer P, Gallinet E, Benmansour A, Despaux J, Toussirot E, Wendling D. Sarcoidosis and spondylarthropathy. Three case-reports. Rev Rhum Engl Ed 1996;63:405-11.

[23] Alijotas-Reig J, Panisello-Royo J. Acute sacroiliac arthritis and sarcoidosis. Rev Rhum Engl Ed 1997;64:278.

[24] Garazi S, Roux S, Palazzo E, Meyer O. [Sarcoidosis and spondyloarthropathy. Apropos of a case]. Ann Med Interne (Paris) 1998;149:303-4.

[25] Abouzahir A, El Maghraoui A, Tabache F, Bezza A, Chaari J, Ghafir D, et al. [Sarcoidosis and ankylosing spondylitis. A case report and review of the literature]. Ann Med Interne (Paris) 2002;153:407-10.

[26] Gómez-Puerta JA, Musuruana J, Saez C, Cervera R, Font J. [Sarcoidosis as seronegative spondyloarthropathy]. Biomedica 2005;25:435-8.

[27] Alaoui F-Z, Talaoui M, Benamour S. [Osteo-articular manifestations of sarcoidosis]. Presse Med 2005;34:19-24.

[28] Vandergheynst F, Tant L. Sarcoidosis masquerading as ankylosing spondylitis. Eur J Intern Med 2006;17:74. https://doi.org/10.1016/j.ejim.2005.09.014.

[29] Sezer I, Melikoglu MA, Cay HF, Kocabas H, Kacar C. A co-occurrence of sarcoidosis and ankylosing spondylitis: a case report. Rheumatol Int 2008;28:605-7. https://doi.org/10.1007/s00296-007-0483-6.

[30] Louie GH, Chitkara P, Ward MM. Relapse of sarcoidosis upon treatment with etanercept. Ann Rheum Dis 2008;67:896-8. https://doi.org/10.1136/ard.2007.078840.

[31] Levy S, Sandhu V. Ankylosing spondylitis and pulmonary sarcoidosis--a case report and discussion of the literature. Rheumatology (Oxford) 2008;47:1733-4. https://doi.org/10.1093/rheumatology/ken366.

[32] Agrawal S, Bhagat S, Dasgupta B. Sarcoid sacroiliitis: successful treatment with infliximab. Ann Rheum Dis 2009;68:283. https://doi.org/10.1136/ard.2007.087155.

[33] Ochi S, Nanki T, Kaneko H, Honne K, Miyazaki Y, Komano Y, et al. Successful treatment of ankylosing spondylitis coexisting with pulmonary sarcoidosis by infliximab. Clin Exp Rheumatol 2009;27:698-9.

[34] Malaviya AN, Sawhney S, Kapoor S, Garg S. Vertebral sarcoid mimicking ankylosing spondylitis or just a co-incidence? J Assoc Physicians India 2010;58:709-11.

[35] Gürer G, Unubol Al, Bozbaş3 GT. A Case of Sacroiliitis Developing After Löfgren's Syndrome. Arch Rheumatol 2011;26:265-8. https://doi.org/10.5152/tjr.2011.043.

[36] El Ouazzani FZ, Tahiri L, Akasbi N, Kadi N, Harzy T. Sarcoidose et spondylarthrite ankylosante: une association rare. Pan Afr Med J 2011;8.

[37] Briongos-Figuero LS, Ruiz-de-Temiño Á, Pérez-Castrillón JL. Sarcoidosis and sacroiliitis, a case report. Rheumatol Int 2012;32:2949-50. https://doi.org/10.1007/s00296-011-2100-y.

[38] Kara M, Özçakar L, Kalyoncu F, Akinci2 A. Early Undifferentiated Spondyloarthropathy in a Patient with Sarcoidosis. Arch Rheumatol 2013;28:206-8. https://doi.org/10.5606/tjr.2013.3000.

[39] Kobak S, Sever F, Sivrikoz O, Karaarslan A. Coexistence of Ankylosing Spondylitis and Löfgren's Syndrome. Case Reports in Rheumatology 2014;2014. https://doi.org/10.1155/2014/747698.

[40] Kobak S, Karaarslan A, Aycan H. Unilateral lymphedema as first presentation of sarcoidosis. Reumatol Clin 2016;12:59-60. https://doi.org/10.1016/j.reuma.2015.03.014.

[41] Wafa H, Saoussen M, Dhia K, Imen Z, Montacer KM. Sarcoidosis and spondyloarthritis: A coincidence or common etiopathogenesis? Caspian J Intern Med 2017:9:100-3.

https://doi.org/10.22088/cjim.9.1.100. 
[42] Rahul CD, Sharma RK, Talwar D. Sarcoidosis with ankylosing spondylitis: changing therapeutic landscape. 1 2018;35:285-8.

[43] Brun J, Pozzetto H, Buffat JJ, Soustelle J, Vauzelle JL, Patin R. [Vertebral and sacroiliac sarcoidosis with image of Pott's pseudo-abscess. Cure by corticotherapy]. Presse Med 1966;74:511-6.

[44] Mijiyawa M, Fereres M, Deutsch JP, Awada H, Dougados M, Amor B. [Pelvi-rachidian involvement in sarcoidosis. Apropos of a case. Review of the literature]. Rev Rhum Mal Osteoartic 1989;56:529-32.

[45] Golzarian J, Matos C, Golstein M, Stallenberg B, Depierreux M, Struyven J. Case report: Osteosclerotic sarcoidosis of spine and pelvis: plain film and magnetic resonance imaging findings. Br J Radiol 1994;67:401-4. https://doi.org/10.1259/0007-1285-67-796-401.

[46] Benelhadj S, Patrois F, Duet M, Bérolatti B, Mundler O. Radioisotope bone scanning in chronic osseous sarcoidosis. Clin Nucl Med 1996;21:371-4.

[47] Franco M, Passeron C, Tieulie N, Verdier JF, Benisvy D. Long-term radiographic follow-up in a patient with osteosclerotic sarcoidosis of the spine and pelvis. Rev Rhum Engl Ed 1998;65:58690.

[48] Andres E, Loth F, Orion B, Marcellin L, Durckel J. Iliac bone defects revealing systemic sarcoidosis. Joint Bone Spine 2001;68:74-5.

[49] Wu C-H, Chung P-I, Wu C-Y, Chen Y-T, Chiu Y-W, Chang Y-T, et al. Comorbid autoimmune diseases in patients with sarcoidosis: A nationwide case-control study in Taiwan. J Dermatol 2017;44:423-30. https://doi.org/10.1111/1346-8138.13654.

[50] Heidelberger V, Ingen-Housz-Oro S, Marquet A, Mahevas M, Bessis D, Bouillet L, et al. Efficacy and Tolerance of Anti-Tumor Necrosis Factor a Agents in Cutaneous Sarcoidosis: A French Study of 46 Cases. JAMA Dermatol 2017;153:681-5. https://doi.org/10.1001/jamadermatol.2017.1162.

[51] Baeten D, Sieper J, Braun J, Baraliakos X, Dougados M, Emery P, et al. Secukinumab, an Interleukin-17A Inhibitor, in Ankylosing Spondylitis. N Engl J Med 2015;373:2534-48. https://doi.org/10.1056/NEJMoa1505066.

[52] Ten Berge B, Paats MS, Bergen IM, van den Blink B, Hoogsteden HC, Lambrecht BN, et al. Increased IL-17A expression in granulomas and in circulating memory $T$ cells in sarcoidosis. Rheumatology (Oxford) 2012;51:37-46. https://doi.org/10.1093/rheumatology/ker316.

[53] Ostadkarampour M, Eklund A, Moller D, Glader P, Olgart Höglund C, Lindén A, et al. Higher levels of interleukin IL-17 and antigen-specific IL-17 responses in pulmonary sarcoidosis patients with Löfgren's syndrome. Clin Exp Immunol 2014;178:342-52. https://doi.org/10.1111/cei.12403.

[54] Mau W, Zeidler H, Mau R, Majewski A, Freyschmidt J, Stangel W, et al. Clinical features and prognosis of patients with possible ankylosing spondylitis. Results of a 10-year followup. J Rheumatol 1988;15:1109-14.

[55] Christiansen AA, Hendricks O, Kuettel D, Hørslev-Petersen K, Jurik AG, Nielsen S, et al. Limited Reliability of Radiographic Assessment of Sacroiliac Joints in Patients with Suspected Early Spondyloarthritis. J Rheumatol 2017;44:70-7. https://doi.org/10.3899/jrheum.160079.

[56] Arnbak B, Grethe Jurik A, Hørslev-Petersen K, Hendricks O, Hermansen LT, Loft AG, et al. Associations Between Spondyloarthritis Features and Magnetic Resonance Imaging Findings: A Cross-Sectional Analysis of 1,020 Patients With Persistent Low Back Pain. Arthritis \& Rheumatology (Hoboken, NJ) 2016;68:892-900. https://doi.org/10.1002/art.39551.

[57] Baraliakos X, Richter A, Feldmann D, Ott A, Buelow R, Schmidt CO, et al. Frequency of MRI changes suggestive of axial spondyloarthritis in the axial skeleton in a large population-based cohort of individuals aged $<45$ years. Ann Rheum Dis 2020;79:186-92. https://doi.org/10.1136/annrheumdis-2019-215553.

[58] Arnbak B, Jurik AG, Jensen TS, Manniche C. Association Between Inflammatory Back Pain Characteristics and Magnetic Resonance Imaging Findings in the Spine and Sacroiliac Joints. Arthritis Care Res (Hoboken) 2018;70:244-51. https://doi.org/10.1002/acr.23259. 
[59] Eno J-JT, Boone CR, Bellino MJ, Bishop JA. The prevalence of sacroiliac joint degeneration in asymptomatic adults. J Bone Joint Surg Am 2015;97:932-6. https://doi.org/10.2106/JBJS.N.01101.

[60] Chan J, Sari I, Salonen D, Inman RD, Haroon N. Development of a Screening Tool for the Identification of Sacroiliitis in Computed Tomography Scans of the Abdomen. J Rheumatol 2016;43:1687-94. https://doi.org/10.3899/jrheum.150939. 